\title{
ĐA DẠNG THÀNH PHẦN LOÀI ĐỘNG VẠTT ĐÁY (ZOOBENTHOS) Ở SÔNG TRUỒI, HUYỆN PHÚ LỘC, TİNH THÙAA THIÊN HUẾ
}

\author{
Hoàng Đình Trung \\ Trường Đại học Khoa học, Đại học Huế, 77 Nguyễn Huệ, thành phố Huế
}

Email: Hoangtrung_na_0208@yahoo.com

Đến Tòa soạn: 18/3/2014; Chấp nhận đăng: 12/10/2014

\section{TÓM TẮT}

Nghiên cứu về thành phần loài động vật đáy ở sông Truồi, huyện Phú Lộc, tỉnh Thừa Thiên Huế được thực hiện trên 7 điểm thu mẫu. Đã xác định được 55 loài trai, ốc, tôm, cua, giun ít tơ, giun nhiều tơ và ấu trùng côn trùng ở nước thuộc 31 họ, 48 giống, 14 bộ của 03 ngành. Trong đó; lớp côn trùng (Insecta) có 27 loài thuộc 25 giống, 14 họ, 5 bộ; tiếp đến lớp Chân bụng (Gastropoda) có 9 loài, 8 giống, 4 họ, 2 bộ; lớp Giáp xác (Crustacea) với 8 loài thuộc 5 giống, 3 họ, 1 bộ; lớp Hai mảnh vỏ (Bivalvia) có 5 loài thuộc 5 họ, 5 giống, 3 bộ; lớp Giun nhiều tơ (Polygocheata) có 4 loài thuộc 3 giống, 3 họ và 2 bộ; lớp Giun ít tơ (Olygocheata) có 2 loài, 2 giống, 2 họ và 1 bộ. Tính bình quân, mỗi bộ có 2,21 họ, 3,42 giống và 3,92 loài. Mỗi họ chứa 1,54 giống, 1,77 loài và mỗi giống chứa 1,14 loài.

Tù̀ khóa: động vật đáy; sông Truồi.

\section{MỞ ĐẦU}

Hệ thống thuỷ văn tỉnh Thừa Thiên Huế hết sức phong phú và độc đáo, hầu hết các con sông đan nối vào nhau thành một mạng lưới chằng chịt: sông Ô Lâu, sông Hương, sông Lợi Nông, sông Đại Giang, sông Cống Quan, sông Truồi, sông Nông. Nơi hội tụ của hầu hết các con sông trước khi ra biển là đầm phá Tam Giang - Cầu Hai, có diện tích lớn nhất Đông Nam Á, kéo dài gần 70 cây số dọc bờ biển. Sông Truồi bắt nguồn từ dãy núi Bạch Mã - Hải Vân nơi có độ cao hơn $500 \mathrm{~m}$, chảy theo hướng gần Nam - Bắc đổ vào đầm Cầu Hai và chảy ra biển ở cửa Tư Hiền. Sông Truồi có chiều dài dòng chính là $24 \mathrm{~km}$, diện tích lưu vực là $149 \mathrm{~km}^{2}$, độ dốc bình quân lòng sông là $34,5 \mathrm{~m} / \mathrm{km}$. Ở thượng lưu sông Truồi đã xây dựng hồ chứa Truồi có dung tích 50 triệu $\mathrm{m}^{3}$ phục vụ tưới tiêu và điều tiết nước vùng hạ lưu. Sông Truồi là một trong mười hệ thống sông chính của tỉnh Thừa Thiên Huế, góp phần tạo nên diện mạo sinh thái cảnh quan và phát triển kinh tế xã hội huyện Phú Lộc; là nơi đáp ứng nhu cầu tưới tiêu, nuôi trồng thuỷ sản, hạn chế lũ lụt, cung cấp nước sinh hoạt cho các địa phương trong vùng. Ngoài các ưu thế để phát triển kinh tế - xã hội, sông Truồi còn chứa trong mình tài nguyên sinh học khá phong phú và đa dạng. Bài báo công bố kết quả nghiên cứu đa dạng về thành phần loài động vật đáy ở sông Truồi 
làm cơ sở dữ liệu khoa học định hướng cho việc khai thác, bảo vệ nguồn lợi và quản lý tổng hợp tài nguyên sinh học ở sông này.

\section{2. ĐỐI TƯợNG VÀ PHƯƠNG PHÁP NGHIÊN CÚU}

\section{1. Đối tượng và địa điểm nghiên cứu}

Đối tượng nghiên cứu là thành phần loài động vật đáy ở sông Truồi, huyện Phú Lộc, tỉnh Thừa Thiên Huế. Địa điểm nghiên cứu là sông Truồi chảy qua địa phận xã Lộc Hòa và Lộc Điền, huyện Phú Lộc. Tiển hành thu thập mẫu theo 7 điểm trên sông Truồi từ tháng 1 năm 2013 đến tháng 2 năm 2014, tuân thủ quy phạm điều tra cơ bản do UBKH\&KT Nhà nước, nay là Bộ Khoa học và Công nghệ ban hành năm 1981.

Bảng 1. Các điểm thu mẫu động vật đáy ở sông Truồi.

\begin{tabular}{|c|l|c|}
\hline Stt & \multicolumn{1}{|c|}{ Địa điểm thu mẫu } & Ký hiệu \\
\hline 1 & Cầu Máng - Lộc Hòa & M1 \\
\hline 2 & Thôn Lương Điền Thương - Lộc Hòa & M2 \\
\hline 3 & Thôn Đồng Xuân - Lộc Hòa & M3 \\
\hline 4 & Cầu Truồi - Lộc Điền & M4 \\
\hline 5 & Thôn An Đông - Lộc Hòa & M5 \\
\hline 6 & Chợ Đông An - Lộc Hòa & M6 \\
\hline 7 & Thôn Miên Nha - Lộc Hòa & M7 \\
\hline
\end{tabular}

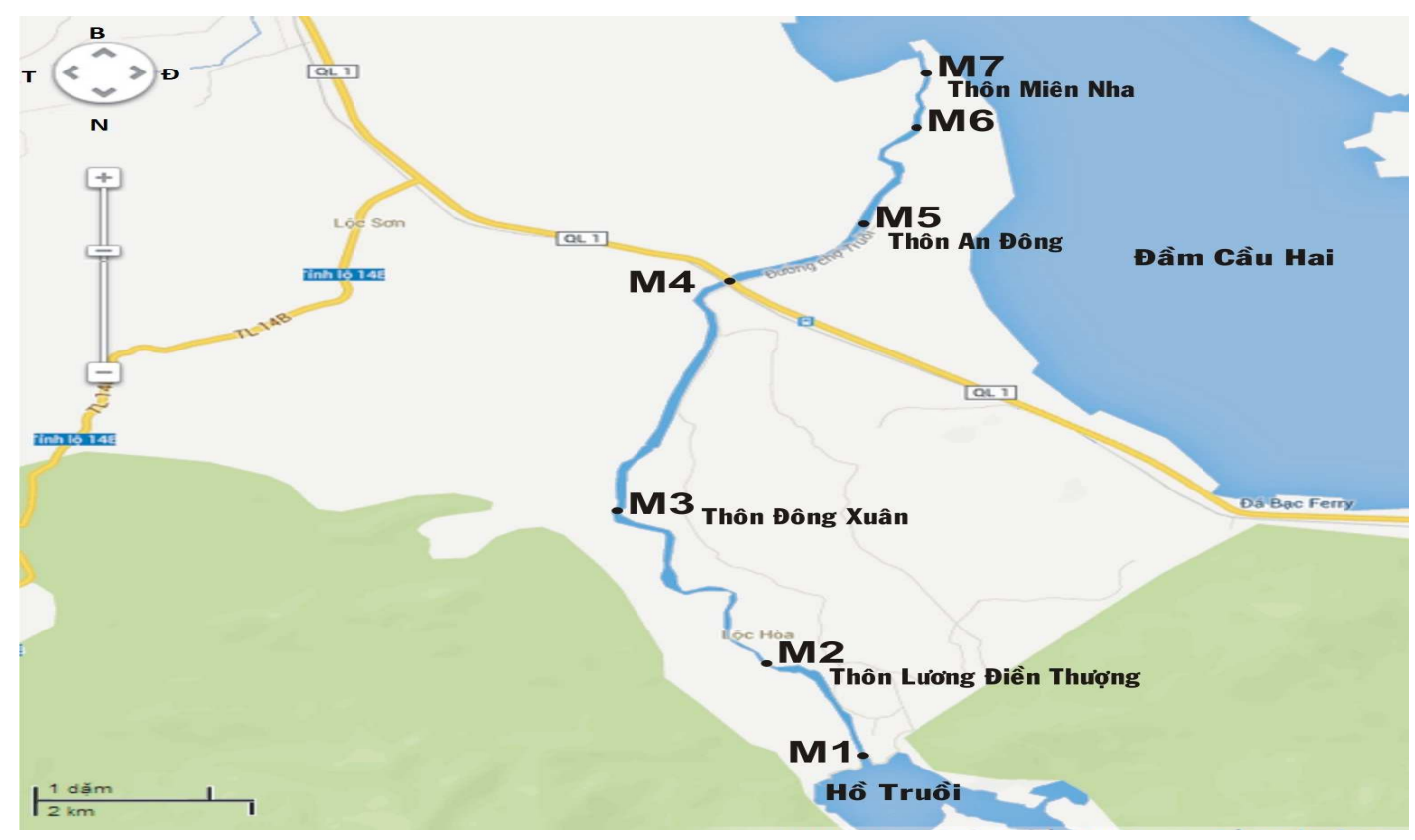

Hình 1. Sơ đồ vị trí các điểm thu mẫu động vật đáy ở sông Truồi. 


\subsection{Phương pháp thu mẫu và định loại}

Mẫu động vật đáy được thu bằng vợt ao (pond net), vợt tay (hand net) và gầu đáy Petersen có diện tích là $0,025 \mathrm{~m}^{2}$. Mẫu côn trùng nước thu thập theo phương pháp của McCafferty W. P. và Provonsha $A$. W [1] và Edmunds $G$. F. Jr. và các CS [2]. Các mẫu được cố định trong formol $4 \%$ ngay sau khi thu mẫu. Mẫu sau khi thu về được phân tích đánh mã số và chuyển sang bảo quản trong cồn $70^{\circ}$. Tiến hành định loại hình thái theo khóa lưỡng phân của Dudgeon D. [3]; Köhler F. và các CS [4]; Michael Quigley [5]; Nguyễn Xuân Quýnh, Clive Pinder, Steve Tilling [6]; Sangradub N. và Boonsoong B. [7]; Đặng Ngọc Thanh và các CS [8, 9, 10]; cũng như Ward J. V. [11].

\section{KẾT QUẢ NGHIÊN CÚU}

\subsection{Thành phần loài động vật đáy sông Truồi}

Đã xác định được 55 loài động vật đáy ở sông Truồi thuộc 31 họ, 48 giống, 14 bộ và 3 ngành. Trong đó, lớp Giun nhiều tơ (Polycheata) có 4 loài thuộc 3 giống, 3 họ và 2 bộ; lớp Giun ít tơ (Olygocheata) có 2 loài, 2 giống, 2 họ và 1 bộ; lớp Chân bụng (Gastropoda) có 9 loài thuộc 4 họ, 2 bộ, 8 giống; lớp Hai mảnh vỏ (Bivalvia) có 5 loài thuộc 5 họ, 3 bộ, 5 giống; lớp Giáp xác (Crustacea) với 8 loài thuộc 5 giống, 3 họ, 1 bộ; lớp Côn trùng (Insecta) với 27 loài thuộc 25 giống, 14 họ, 5 bộ (bảng 2).

Về bậc họ: Trong tổng số 31 họ, ngành Chân khớp (Arthropoda) có 17 họ (chiếm 54,84 $\%$ ); ngành Thân mềm (Mollusca) 9 họ (chiếm 29,03 \% tồng số họ); ngành giun đốt (Annelida) với 5 họ (chiếm 16,13\%). Họ có số giống cao nhất (3 giống, chiếm 6,25\%) là họ Viviparidae và Gerridae; tiếp đến là các họ Ampullaridae, Thiaridae, Palaemonidae, Parathelphusidae, Gomphidae, Dytiscidae, Noteridae, Hydrophilidae, Psephenidae, Scirtidae, Naucoridae, Tipulidae, Heptageniidae mỗi họ có 2 giống (chiếm 4,17 \%); các họ còn lại mỗi họ chỉ có 1 giống (chiếm 2,08 \% tổng số giống) .

Về bậc giống: Chiếm ưu thế nhất thuộc về lớp Côn trùng với 25 giống (chiếm 52,08\% tổng số giống), lớp Chân bụng có 8 giống (chiếm 16,67 \%), lớp Hai mảnh vỏ và lớp Giáp xác cùng có 5 giống (chiếm 10,42 \%), lớp Giun nhiều tơ 3 giống (chiếm 6,25\%), lớp Giun ít tơ 2 giống (chiếm $4,17 \%$ ).

Về bậc loài: Ngành Chân khớp chiếm ưu thế nhất với 35 loài (chiếm 63,64\%), tiếp đến là ngành Thân mềm với 14 loài (chiếm 25,45\%), ngành Giun đốt có 6 loài (chiếm 10,91\%). Lớp Côn trùng với 27 loài (chiếm 49,09\%), lớp Chân bụng có 9 loài (chiếm 16,36 \%), lớp Giáp xác với 8 loài (chiếm 14,55\%), lớp Hai mảnh vỏ có 5 loài (chiếm 9,09\%), lớp Giun nhiều tơ có 4 loài (chiếm 7,27 \%), lớp Giun ít tơ có 2 loài (chiếm 3,64 \%).

Sự đa dạng về số lượng loài trong các giống: Giống Macrobrachium có số lượng loài cao nhất với 4 loài (chiếm 7,27 \% tổng số loài); tiếp đến là bốn giống Lymnaea, Nephthys, Chironomus, Ephemera, mỗi giống chứa 2 loài (chiếm 3,64 \%); 43 giống còn lại chỉ có 1 loài (chiếm 1,82\%). 
Bảng 2. Số lượng các họ, giống và loài động vật đáy ở sông Truồi.

\begin{tabular}{|c|c|c|c|c|c|c|c|}
\hline Stt & Tên lớp & Tên họ & Số loài & Tỉ lệ \% & Tên giống & Số loài & Tỷ lệ \% \\
\hline \multirow{8}{*}{1} & \multirow{8}{*}{ Gastropoda } & \multirow{2}{*}{ Ampullaridae } & \multirow{2}{*}{2} & \multirow{2}{*}{3,64} & Pomacea & 1 & 1,82 \\
\hline & & & & & Pila & 1 & 1,82 \\
\hline & & \multirow{2}{*}{ Thiaridae } & \multirow{2}{*}{2} & \multirow{2}{*}{3,64} & Melanoides & 1 & 1,82 \\
\hline & & & & & Semyla & 1 & 1,82 \\
\hline & & \multirow{3}{*}{ Viviparidae } & \multirow{3}{*}{3} & \multirow{3}{*}{5,45} & Angulyagra & 1 & 1,82 \\
\hline & & & & & Sinotaia & 1 & 1,82 \\
\hline & & & & & Filopaludina & 1 & 1,82 \\
\hline & & Lymnaeidae & 2 & 3,64 & Lymnaea & 2 & 3,64 \\
\hline \multirow{5}{*}{2} & \multirow{5}{*}{ Bivalvia } & Unionidae & 1 & 1,82 & Cristaria & 1 & 1,82 \\
\hline & & Mytilidae & 1 & 1,82 & Limnoperna & 1 & 1,82 \\
\hline & & Pisidiidae & 1 & 1,82 & Afropisidium & 1 & 1,82 \\
\hline & & Corbiculidae & 1 & 1,82 & Corbicula & 1 & 1,82 \\
\hline & & Amblemidae & 1 & 1,82 & Oxynaia & 1 & 1,82 \\
\hline \multirow{3}{*}{3} & \multirow{3}{*}{ Polychaeta } & Sabellidae & 1 & 1,82 & Laonome & 1 & 1,82 \\
\hline & & Opheliidae & 1 & 1,82 & Ophelina & 1 & 1,82 \\
\hline & & Nephthydidae & 2 & 3,64 & Nephthys & 2 & 3,64 \\
\hline \multirow{2}{*}{4} & \multirow{2}{*}{ Oligochaeta } & Naididae & 1 & 1,82 & Slavina & 1 & 1,82 \\
\hline & & Tubificidae & 1 & 1,82 & Branchiura & 1 & 1,82 \\
\hline \multirow{5}{*}{5} & \multirow{5}{*}{ Crustacea } & \multirow[t]{2}{*}{ Palaemonidae } & \multirow[t]{2}{*}{5} & \multirow[t]{2}{*}{9,09} & Macrobrachium & 4 & 7,27 \\
\hline & & & & & Palaemonetes & 1 & 1,82 \\
\hline & & Atyidae & 1 & 1,82 & Caridina & 1 & 1,82 \\
\hline & & \multirow{2}{*}{ Parathelphusidae } & \multirow{2}{*}{2} & \multirow{2}{*}{3,64} & Somanniathelphusa & 1 & 1,82 \\
\hline & & & & & Varuna & 1 & 1,82 \\
\hline & & Chironomidae & 2 & 3,64 & Chironomus & 2 & 3,64 \\
\hline & & Tinulido & 2 & 261 & Antocha & 1 & 1,82 \\
\hline & & Tipuntac & 2 & , & Limnophila & 1 & 1,82 \\
\hline & & Comolidos & 2 & 261 & Heliogomphus & 1 & 1,82 \\
\hline & & Gompminae & 2 & 3,04 & Leptogomphus & 1 & 1,82 \\
\hline & & Dyticcidne & 2 & 364 & Laccophilus & 1 & 1,82 \\
\hline & & Dyusciuat & 2 & 3,04 & Hydrovatus & 1 & 1,82 \\
\hline & & Noteridae & 2 & 364 & Noterus & 1 & 1,82 \\
\hline 6 & Insecta & Noternate & 2 & 3,04 & Carthydrus & 1 & 1,82 \\
\hline & & Girinidae & 1 & 1,82 & Orectochilus & 1 & 1,82 \\
\hline & & Hydronhilidae & 2 & 364 & Berosus & 1 & 1,82 \\
\hline & & пусторпппиае & 2 & 3,04 & Helochares & 1 & 1,82 \\
\hline & & Psenhenidae & 2 & 364 & Psephenus & 1 & 1,82 \\
\hline & & & 2 & 3,04 & Eubrianax & 1 & 1,82 \\
\hline & & Scirtidae & 2 & 364 & Cyphon & 1 & 1,82 \\
\hline & & & & & Prionocyphon & 1 & 1,82 \\
\hline & & Gerridae & 3 & 5,45 & Amemboa & 1 & 1,82 \\
\hline
\end{tabular}




\begin{tabular}{|c|c|c|c|c|c|c|}
\hline & & & & Aquarius & 1 & 1,82 \\
\hline & & & & Rhyacobates & 1 & 1,82 \\
\hline & \multirow{2}{*}{ Naucoridae } & \multirow{2}{*}{2} & \multirow{2}{*}{3,64} & Pelocoris & 1 & 1,82 \\
\hline & & & & Gestroiella & 1 & 1,82 \\
\hline & Ephemeridae & 2 & 3,64 & Ephemera & 2 & 3,64 \\
\hline & \multirow{2}{*}{ Heptageniidae } & \multirow{2}{*}{2} & \multirow{2}{*}{3,64} & Asionurus & 1 & 1,82 \\
\hline & & & & Epeorus & 1 & 1,82 \\
\hline & Potamanthidae & 1 & 1,82 & Rhoenanthus & 1 & 1,82 \\
\hline Tổng & 31 & 55 & 100 & 48 & 55 & 100 \\
\hline
\end{tabular}

\subsection{Các loài bổ sung mới cho khu hệ động vật đáy sông Truồi}

So sánh với kết quả nghiên cứu trong năm 2013 của Hoàng Đình Trung [12], nay bổ sung mới cho thành phần loài động vật đáy ở sông Truồi gồm 29 loài, 27 giống, (Nephthys, Ophelina, Laonome, Slavina, Branchiura, Laccophilus, Hydrovatus, Noterus, Carthydrus, Orectochilus, Berosus, Helochares, Psephenus, Eubrianax, Cyphon, Prionocyphon, Amemboa, Aquarius, Rhyacobates, Pelocoris, Gestroiella, Antocha, Limnophila, Ephemera, Asionurus, Epeorus, Rhoenanthus) và 17 họ thuộc 06 bộ và 03 lớp khác nhau (Bảng 3). Trong 29 loài bổ sung mới cho thành phần loài động vật đáy sông Truồi, chiếm ưu thế nhất là ấu trùng côn trùng nước với 23 loài (chiếm 79,31 \% tổng số loài bổ sung mới). Hầu hết các ấu trùng côn trùng nước mới xác định ở taxon bậc giống và những giống này được ghi nhận lần đầu tiên cho sông Truồi trong nghiên cứu này. Để có thông tin chính xác tới loài cần phải có những nghiên cứu bổ sung ở pha trưởng thành trong nghiên cứu tiếp theo.

Bảng 3. Danh sách các loài mới bổ sung cho thành phần loài động vật đáy ở sông Truồi.

\begin{tabular}{|c|l|c|l|}
\hline Stt & \multicolumn{1}{|c|}{ Tên khoa học } & Stt & \multicolumn{1}{|c|}{ Tên khoa học } \\
\hline & NGÀNH GIUN ĐỐT - ANNELIDA & $\mathbf{( 9 )}$ & Họ Hydrophilidae \\
\hline I & LỚP GIUN NHIÊU TÓ - POLYCHAETA & 12 & Berosus sp. \\
\hline & Bộ Nereimorpa & 13 & Helochares sp. \\
\hline $\mathbf{( 1 )}$ & Họ Nephthydidae & $\mathbf{( 1 0 )}$ & Họ Psephenidae \\
\hline 1 & Nephthys polybranchia Southern, 1921 & 14 & Psephenus sp. \\
\hline 2 & Nephthys dibranchis Grube, 1877 & 15 & Eubrianax sp. \\
\hline & Bộ Phyllodocemorpha & $\mathbf{( 1 1 )}$ & Họ Scirtidae \\
\hline$(2)$ & Họ Opheliidae & 16 & Cyphon sp. \\
\hline 3 & Ophelina sp. & 17 & Prionocyphon sp. \\
\hline$(3)$ & Họ Sabellidae & & Bộ cánh nửa - Hemiptera \\
\hline 4 & Laonome kroyeri Sars, 1901 & $\mathbf{( 1 2 )}$ & Họ Gerridae \\
\hline II & LỚP GIUN ÍT TÓ - OLIGOCHAETA & 18 & Amemboa sp. \\
\hline & Bộ Plesiophora & 19 & Aquarius sp. \\
\hline
\end{tabular}




\begin{tabular}{|c|c|c|c|}
\hline (4) & Họ Naididae & 20 & Rhyacobates sp. \\
\hline 5 & Slavina appendiculata Udekem, 1929 & (13) & Họ Naucoridae \\
\hline (5) & Họ Tubificidae & 21 & Pelocoris sp. \\
\hline \multirow[t]{2}{*}{6} & Branchiura sowerbyi Beddard, 1906 & 22 & Gestroiella sp. \\
\hline & NGÀNH CHÂN KHỚP - ARTHROPODA & (14) & Họ Tipulidae \\
\hline \multirow[t]{2}{*}{ VI } & LỚP CÔN TRÙNG - INSECTA & 23 & Antocha sp. \\
\hline & Bộ cánh cứng - Coleoptera & 24 & Limnophila sp. \\
\hline (6) & Họ Dytiscidae & & Bộ Phù du - Ephemeroptera \\
\hline 7 & Laccophilus sp. & (15) & Ephemeridae \\
\hline 8 & Hydrovatus sp. & 25 & Ephemera $\mathrm{sp}_{1}$. \\
\hline (7) & Họ Noteridae & 26 & Ephemera $\mathrm{sp}_{2}$. \\
\hline 9 & Noterus sp. & (16) & Heptageniidae \\
\hline 10 & Carthydrus sp. & 27 & $\begin{array}{l}\text { Asionurus primus Braasch \& Soldán, } \\
1984\end{array}$ \\
\hline (8) & Họ Girinidae & 28 & Epeorus sp. \\
\hline \multirow[t]{2}{*}{11} & Orectochilus sp. & (17) & Potamanthidae \\
\hline & & 29 & Rhoenanthus sp. \\
\hline
\end{tabular}

\section{KẾT LUẬN}

Thành phần loài động vật đáy ở sông Truồi, huyện Phú Lộc, tỉnh Thừa Thiên Huế khá đa dạng. Đã xác định được 55 loài trai, ốc, tôm, cua, giun ít tơ, giun nhiều tơ và ấu trùng côn trùng ở nước thuộc 31 họ, 48 giống, 14 bộ của 03 ngành. Trong đó, chiếm ưu thế nhất thuộc về lớp Côn trùng (Insecta) có 27 loài thuộc 25 giống, 14 họ, 5 bộ; tiếp đến lớp Chân bụng (Gastropoda) có 9 loài, 8 giống, 4 họ, 2 bộ; lớp Giáp xác (Crustacea) với 8 loài thuộc 5 giống, 3 họ, 1 bộ; lớp Hai mảnh vỏ (Bivalvia) có 5 loài thuộc 5 họ, 5 giống, 3 bộ; lớp Giun nhiều tơ (Polygocheata) có 4 loài thuộc 3 giống, 3 họ và 2 bộ; lớp Giun ít tơ (Olygocheata) có 2 loài, 2 giống, 2 họ và 1 bộ. Tính bình quân, mỗi bộ có 2,21 họ, 3,42 giống và 3,92 loài. Mỗi họ chứa 1,54 giống, 1,77 loài và mỗi giống chứa 1,14 loài.

Đã bổ sung mới cho thành phần loài động vật đáy sông Truồi 29 loài, 27 giống, 17 họ của 6 bộ và 03 lớp: lớp Giun ít tơ, Giun nhiều tơ và Côn trùng. Trong đó ấu trùng Côn trùng nước chiếm $79,31 \%$ tổng số loài bổ sung mới.

\section{TÀI LIỆU THAM KHẢO}

1. McCafferty W. P. and Provonsha A. W. - Aquatic Entomology, Boston: Jones \& Bartlett Publishers, 1981, 448pp.

2. Edmunds Jr. G. F., et al. - The Mayflies of North and Central America, Univ. Minnesota Press, Minneapolis, 1976, 330pp. 
3. Dudgeon D. - Tropical Asian Streams. Zoobenthos, Ecology and Conservation, Hong Kong University Press, Hong Kong (1999), 830 p.

4. Köhler F. et al. - Exploring a largely unknown fauna: on the diversity of pachychilid freshwater gastropods in Vietnam (Caenogastropoda: Cerithioidea). Mollus. Molluscan Research 29 (3) (2009) 121-146.

5. Michael Quigley - Key to the Invertebrate animals of streams and rivers, 1993, Nene college Northampton, pp. 37-55.

6. Nguyễn Xuân Quýnh, Clive Pinder, Steve Tilling - Định loại các nhóm động vật không xương sống nước ngọt thường gặp ở Việt Nam. Nxb. Đại học Quốc gia Hà Nội, 2001.

7. Sangradub N. and Boonsoong B. - Identification of Freshwater Invertebrates of the Mekong River and Tributaries. Thailand: Mekong River Commission, 2004, 276pp.

8. Đặng Ngọc Thanh, Thái Trần Bái, Phạm Văn Miên - Định loại động vật không xương sống nước ngọt Bắc Việt Nam. Nxb. Khoa học \& Kỹ thuật, Hà Nội, (1980), 573 tr.

9. Đặng Ngọc Thanh, Hồ Thanh Hải - Giáp xác nước ngọt, Động vật chí Việt Nam, tập 5. Nxb. Khoa học và Kỹ thuật, Hà Nội, 2001, 239 tr.

10. Đặng Ngọc Thanh, Hồ Thanh Hải - Họ ốc nước ngọt Pachychilidae Troschel, 1857 (Gastropoda - Prosobranchia - Cerithioidea) ở Việt Nam, Tạp chí Sinh học 29 (2) (2007) $1-8$.

11. Ward J. V. - Aquatic Insect Ecology, America: John Wiley \& Sons, Vol. 1, 1992, 456pp.

12. Hoàng Đình Trung - Bước đầu nghiên cứu về thành phần loài động vật không xương sống cỡ lớn ở sông Truồi, huyện Phú Lộc, tỉnh Thừa Thiên Huế, Tạp chí Khoa học Đại học Huế (84) (2013) 133-140.

\title{
ABSTRACT \\ DIVERSITY OF ZOOBENTHOS IN TRUOI RIVER, PHU LOC DISTRICT, THUA THIEN HUE PROVINCE
}

\author{
Hoang Dinh Trung \\ College of Science, Hue University, 77 Nguyen Hue street, Hue city \\ Email: Hoangtrung_na_0208@yahoo.com
}

The main objective of this study was to research of diversity composition species Zoobenthos in Truoi river, Thua Thien Hue province. The study was carried out in January of 2013 to February of 2014. As the results 55 species of zoobenthos belonging to 48 genera, 31 families were recorded. As it is showed the Insecta were the most abundant with 27 species, 25 genera and 14 families, 5 orders; next is the Crustacea with 8 species, 5 genera, 3 families, 1 order; the Bivalvia with 5 species, 5 genera, 5 families, 3 orders; the Polygocheata with 4 species, 3 genera, 3 families and 2 orders; the Olygocheata with 2 species, 2 genera, 2 families and 1 order. The new checklist adds 29 new species and 27 new genera, 17 families and 6 classes to zoobenthos checklist of Truoi river by Hoang Dinh Trung, 2013.

Keywords: Zoobenthos, Truoi river. 